\title{
Antenatal Screening AndSonological Detection of Urinary Tract Anomalies.
}

\author{
MahaleAjitR ${ }^{1}$.Mahale Nina $^{2}$, FernandesMerwyn $^{3}$, Ullal Sonali $^{4}$ \\ ${ }^{I}$ Department(s) and institution(s) where the work was carried out: Department of Radiodiagnosis and \\ Department of Obstetrics and Gynaecology Kasturba Medical College Mangalore Manipal University. \\ ${ }^{2}$ Department of Radiodiagnosis at KMC Mangalore Manipal University
}

\begin{abstract}
Introduction:Anomalies of the urinary tract are common but the true incidence varies from centre to centre and with the timing of the ultrasound examination. The majority (approximately 70\%) are not lethal and can be treated.

Methods:This study was carried out in the Department of Radiodiagnosis and Imaging and Obstetrics and Gynecology, Machines used where GE Voluson Expert, S7, LOGIC 500 pro,Phillips HD15, HD 11,HD $7 \&$ Envisorultrasound scanners with color doppler. Transducer used for the obstetric scanning was $3.5 \mathrm{MHZ}$ frequency convex probe.Standardizedsonographic technique was used for the obstetric scan adhering to the published guidelines of the American Institute of Ultrasound in Medicine.Sonographic studies were performed on all 31 pregnancies of 16-20 weeks' gestation upto term, irrespective of patients age and parity. Both singleton and multiple gestations were included in the study.

Results:Twenty-three of the total 31 (74\%) had unilateral disease and $8(26 \%)$ had bilateral involvement. Twenty-four of 31 (78\%) survived, without undergoing operative therapy postnatally.Majority of renal abnormalities were not life threatening, however severe bilateral renal abnormalities accounted for $10 \%$ of all terminations for lethal fetal abnormalities

Conclusion:Antenatal diagnosis of fetal urinary tract abnormalities is useful in the prevention of renal damage in the child or young adult and to plan approporiate therapy inutero or post natally.
\end{abstract}

Keywords:antenatal, ultrasound, urinary tract anomalies

\section{Introduction}

Congenital abnormalities of the urinary tract are common but the true incidence is uncertain which varies from centre to centre and with the timing of the ultrasound examination. Although exceeded only by malformation of the central nervous and cardiovascular systems as causes of death in infancy from congenital malformations, the majority (approximately 70\%) are not lethal. This makes assessment of the true incidence very difficult: it is approximately two or three per 1000 live births.Since the information provided by ultrasound evaluation influences obstetric and neonatal management, every obstetric ultrasound study during the second and third trimesters should include documentation of the fetal urinary bladder, evaluation of the fetal kidneys, and assessment of amniotic fluid volume as many genitourinary anomalies are discovered as incidental findings. The move towards a multidisciplinary approach with obstetricians, radiologists ,urologists and paediatricians in close communication will improve the management of such foetuses.

\section{Methods}

This study was carried out in the Department of Radiodiagnosis and Imaging,9600 antenatal patients were screened for anomalies,over a period of 4 years 31 antenatal patients with foetuses having urinary tract anomalies were diagnosed on routine antenatal checkups, after taking informed consent as per PCPNDT rules. Machines used where GE Voluson Expert, S7,LOGIC 500 pro,Phillips HD15, HD 11,HD 7\&Envisor ultrasound scanners with colordoppler. Transducer used for the obstetric scanning was 3.5 MHZ frequency convex probe.

Standardized sonographic technique was used for the obstetric scan adhering to the published guidelines of the American Institute of Ultrasound in Medicine.Sonographic studies were performed on all 31 pregnancies of 16-20 weeks' gestation upto term, irrespective of patients age and parity. Both singleton and multiple gestations were included in the study.

A detailed patient's history was taken for any family history of genitourinary abnormalities, or of any problems manifested secondary to the anomalies, such as fetal demise, oligohydramnios, fetopelvic disproportion during labour. 
On routine scans, if an anomaly was detected, the examination was extended at the same visit, or at a later visit and hard-copy images of fetalanomalies were taken.Patients with foetuses having urogenital anomalies were followed up and we studied the outcome of pregnancy: whether termination of pregnancy was done or patient had a normal vaginal delivery or a caesarean section. Postnatal assessment of the neonate was done by an ultrasound and the neonatal outcome was studied.(Table1)

The obtained results were then compared with previously published series using standarized criteria, modifying published results where necessary to achieve standardization. All cases of fetal anomaly suspected at obstetric sonography were recorded prospectively, and the delivery or autopsy records were subsequently examined.The written report of the sonogram was compared with the postnatally determined congenital anomaly, classifying each anomaly as detected or not detected by sonography, for sonograms obtained before and after 20 weeks' gestation, which is the legal limit for termination of pregnancy.Pregnancy outcome was reported as termination of pregnancy, death (from 16 weeks' gestation to 1 month of postnatal age), adverse outcome (born alive with a major malformation), or no adverse outcome (born with a minor malformation).Anomalies are reported in percentage terms for the overall detection rate. In addition, a detection rate of anomalies per 1000 pregnancies screened was also reported..(Table $2 \& 3$ )

\section{Results}

The prenatal diagnosis of a urogenital anomaly was made in 31 fetuses from scanning performed over a 4-year period on all pregnancies having attained 16-20 weeks' gestation upto term, irrespective of patients age and parity.Sonographic findings, antenatal course and postnatal outcome were examined.The number of obstetric ultrasound scans performed after 16 weeks' gestation were relatively more than those done at 16-20 weeks' gestation.Study cases included only those renal anomalies that were clinically apparent within 1 month of birth.No interventional therapy was undertaken in utero, and the natural history could be examined in the 24 of 31 patients $(78 \%)$ who did not electively terminate their pregnancies. Twenty-three of the total $31(74 \%)$ had unilateral disease and $8(26 \%)$ had bilateral involvement.Twenty-four of $31(78 \%)$ survived, without undergoing operative therapy postnatally.In all of the 24 survivors, the anomaly was isolated to the genitourinary tract, and the majority of surviving fetuses had unilateral disease.

Majority of renal abnormalities were not life threatening, however severe bilateral renal abnormalities accounted for $10 \%$ of all terminations for lethal fetal abnormalities.Severe oligohydramnios was present in only 3 of the 7 women $(43 \%)$ who underwent termination and none among them had polyhydramnios.(Table 4)All three of these fetuses had bilateral disease with severe oligohydramnios.Seven of 31 women underwent termination of pregnancy and none experienced a neonatal death.A high incidence of urinary tract abnormalities were also detected in third trimester scans, 15 cases out of total 31 cases $(48.4 \%)$.

The final diagnosis in 19 fetuses with antenatal diagnosis of unilateral/bilateral hydronephrosis showed that $47.3 \%$ cases were due to pelviureteric junction- PUJ defect, $21.1 \%$ cases were due to vescicoureteric junction- VUJ defect, $10.5 \%$ cases were due to vescico ureteric reflux-VUR, $10.5 \%$ were due to posterior urethral valve-PUV, $5.26 \%$ were due to obstruction secondary to ureterocele and remaining $5.26 \%$ were due to urethral atresia.

In the total study figures and while comparing results with prior studies, we included all minor relatively common fetal renal anomalies for example renal dilatation, but excluded 7 cases of renal dilatation from the figures reported because no postnatal follow-up was available.Significant false-positive rate ranging between 39 to $52 \%$ was noted mainly due to the detection of mild hydronephrosis which was subsequently found to be normal after birth.

Evaluation of fetal autopsies following termination of pregnancy correlated well with the urogenital anomalies detected in mid trimester prenatal ultrasound in all the cases. Two cases of horseshoe shaped kidneys were suspected on prenatal sonograms that were not confirmed during 1 month postnatal scans (false-positives): Kidneys were normal postnatally-Hence, these cases were excluded from the total study cases.Only two genital tract anomalies were diagnosed during the study, one case of bilateral hydrocele and another case of right sided ovarian cyst which were confirmed postnatally. The majority of fetuses with a genitourinary anomaly did well postnatally.

\section{Discussion}

Anomalies of the kidney and urinary tract account for approximately 20-30\% of all anomalies identified in the prenatal period.Antenatal diagnosis indicates the need for early termination of pregnancy in fatal renal disease helps in planning for serious neonatal problems that may be detected postnatally. Any renal malformation is an indication for evaluation of the fetus for other anomaly(s) and syndromic cause like short rib poldactyly syndrome. ${ }^{1}$

Antenatal hydronephrosis is detected in fetuses during the second and third trimesters by ultrasonography Mild, isolated ANH represents up to $80 \%$ of cases and is considered to be more benign than 
those of moderate or severe grades . Majority of the cases of mild ANH are benign, $10 \%$ may have significant urological pathologies and may develop complications such as febrile urinary tract infection and renal injury if left untreated. Although this grading system is not standardized like theSociety of Fetal Urology (SFU) system, this correlates generally to SFU Grade $1 \& 2$ for mild, SFU Grade 3 for moderate and SFU Grade 4 for severe and is based on theamount of pelvic and calyceal dilatation. This "mild-severe"grading system is the most commonly used system among radiologists and, specifically, pediatric radiologists. ${ }^{2}$

Fetal kidney is typically visualized on a transabdominal ultrasound at approximately 15 weeks of gestation. Fetal renal length varies during development .The anterior posterior diameter (APD) of the fetal renal pelvis is increasingly used to categorize fetal renal dilatation as normal or abnormal. Fetal renal APD measurements less than $4 \mathrm{~mm}$ in the second trimester and less than $7 \mathrm{~mm}$ in the third trimester are considered physiologic levels of fetal renal dilatation.In the normal fetus, the ureters are not visible on prenatal ultrasound whereas normal ureteral diameter in neonates is reported to be $5 \mathrm{~mm}$ or less. The bladder must be visualized, repeat imaging later in the study or on a subsequent repeat ultrasound should confirm its presence or absence. Bladder enlargement, also termed megacystis may be noted on prenatal ultrasound and can suggest urinary tract obstruction. Measurements that define a normal fetal bladder size are not definitive..During 10 to 14 weeks normal parameters for bladder size include either a longitudinal bladder diameter of less than $6 \mathrm{~mm}$ or a diameter measuring less than $10 \%$ of crown rump length. ${ }^{3}$

Normal bladder in the second trimester is one of small size that empties during a 45-minute time frame. Amniotic fluid levels are a marker for fetal urinary tract function. Fetal urine production begins by 8 to 10 weeks of gestation, but its beyond 16 weeks of development that the amniotic fluid is primarily composed of fetal urine. Abnormalities in the amniotic fluid levels in the second and third trimesters are indicators of urinary tract problems. ${ }^{3}$

The role of surgical intervention in children with prenatal hydronephrosis (PHN )are relief of obstruction, preservation of renal function and alleviation of symptoms. It is important to determine which PHN patients will go on to require surgery based on the information available at early ultrasound scan. The degree of hydronephrosis noted can be a guide for further investigations to determine etiology of the dilatation. ${ }^{4}$ Invasive investigations involving IV access and radiation VCUG and nuclear renograms like might be required, and must be used judiciously. Parenchyma to Hydronephrosis Area Ratio (PHAR) at the baseline US allows for early identification of patients who are more likely to undergo surgical intervention, information that is gathered before serial US and renal scan results are available. Furthermore, PHAR values (PHAR cut off value of $<5.5$ to be predictive of the need for surgery). appear to correlate with future nuclear scan parameters, suggesting that there is potential for correlation with renal function and drainage tests. ${ }^{4}$

Severity of Prenatal hydronephrosis (HN) by renal ultrasound helps in guiding evaluation and surgical indications, treatment plans to prevent urinary tract infections (UTIs). HN has been classified by the Society for Fetal Urology (SFU) system into low (I/II) and high grade (III/IV). Shortcomings that have been attributed to the use of the SFU classification in separating grades II and III HN leading to inconsistency in reporting and management. Urinary tract dilatation UTD risk stratification classification has been used to improve previous $\mathrm{HN}$ grading systems, to reduce the standardize HN management. The SFU classification was only taking into account the kidney parameters and not including ureteral dilation, renal dysplasia, and bladder abnormalities, which have now been included in new UTD system. The UTD classification would be able to better predict clinical outcomes as compared to SFU system. It can differentiate isolated HN- Ureteropelvic junction obstruction (UPJO-like) that can be managed non-surgically from true UPJO cases that need surgical intervention. It can establish which patients will ultimately require a pyeloplasty at a young age from those who can wait a bit longer or avoid surgical intervention. ${ }^{5}$

The longitudinal and transverse diameters of the renal pelvis have been shown to correlate with fetalage, weight, and crown-rump length. There is correlation of the renal pelvis parameters with length, width, and thickness of the fetal kidney. ${ }^{6}$ Antenatal hydronephrosis could be caused by multicystic kidneys, primary obstructive megaureter, anomalous ureteropelvicjunction/ureterovescical junction obstruction, ectopic ureter, ectopic ureterocele,Prune belly syndrome, posterior urethral valves, hydrocolpos, urethral atresia, pelvic tumours,cloacal anomaly. Bladder may be distended in some of the above conditions. ${ }^{7}$

Megacystis in the first trimester of gestation occurs in 1 in 1800 pregnancies, and most of these resolve spontaneously. Longitudinal bladder diameter is less than $6 \mathrm{~mm}$ at 10-14 weeks . Bladder diameters greater than $17 \mathrm{~mm}$ in the first trimester is most likely caused by obstructive factors, and experience progressive obstruction, whereas most fetuses with diameters of $8-12 \mathrm{~mm}$ would be resolved by 20 weeks. There is a $25 \%$ risk of an aneuploidy (trisomy 13 and 18) and associated malformations in $33 \%$ of fetuses. ${ }^{7}$

A detailed ultrasound needs to be done to detect other structural anomalies. Fetal karyotyping needs to be done to exclude chromosomal anomalies.Serialfetal urine analysis should be done to rule out renal impairment. ${ }^{7}$

\section{Reported unfavourable prognostic risk factors are:}


1) prolonged oligohydramnios, (2) presence of renal cortical cysts (3)urinary sodium level greater than or equal to $100 \mathrm{mEq} / \mathrm{L}$, chloride level more than $90 \mathrm{mEq} / \mathrm{L}$, osmolarity more than $210 \mathrm{mmol} / \mathrm{L}$ and increased urinary b2-microglobulin level $(>6 \mathrm{mg} / \mathrm{L})$, and (4)reduced lung area and/or thoracoabdominal circumference. ${ }^{7}$ Presence of unilateral or bilateral renal agenesis and dysplastic kidneys could be a part of a genetic disorder. Cystic kidney disease may not be detected by ultrasound at 20 weeks, hence a repeat scan at 28-30 weeks in high risk pregnancies is indicated. ${ }^{8}$ Early onset LUTO(Lower urinary tract obstruction) carries a poor prognosis and termination of pregnancy may be necessary.Significant LUTO that compromises renal function and fetal urine production in the antenatal period can be managed by a urinary diversion by the placement of a vescicoamniotic shunt. ${ }^{8}$ Freedman et al.reported that, among children who survived after antenatal intervention for obstructive uropathies beyond 2 years, 36\% had renal failure and had successful transplantation, $21 \%$ have renal insufficiency, and $43 \%$ had normal renal function. Moreover, 50\% of them had acceptable continence, and most of the remaining children had not begun (36\%) and 14\% were incontinent. Therefore, babies that survive, with or without prenatal intervention, have a significant risk of renal impairment, often necessitating renal dialysis or transplantation in childhood.$^{8}$

\section{Conclusions}

Ultrasonic antenatal diagnosis of fetal urinary tract abnormalities is useful in the prevention of renal damage in the child or young adult and in planning early intervention .

Acknowledgements: Kasturba Medical College Mangalore Manipal University and associated hospitals

\section{References}

[1]. Kumar M, Thakur S, Puri A, Shukla S, Sharma S, Perumal V, Chawla R, Gupta U. Fetal renal anomaly: factors that predict survival.JPediatr Urol. 2014 Dec;10(6):1001-7.

[2]. A. Sencan, F. Carvas, I.C. Hekimoglu, N. Caf, A. Sencan, J. Chow, H.T. Nguyen

[3]. Help. Urinary tract infection and vesicoureteral reflux in children with mild antenatal hydronephrosis. J Pediatr Urol. 2014 Dec;10(6):1008-1013.

[4]. DB.Clayton,JW Brock. Prenatal ultrasound and urological anomalies. Pediatric Clinics of North America 2012; 59(4):739-756.

[5]. Mandy Rickard, Armando J. Lorenzo, Luis H. Braga, Renal Parenchyma to Hydronephrosis Area Ratio (PHAR) as a Predictor of Future Surgical Intervention for Infants with High-Grade Prenatal Hydronephrosis, Urology (2016), http://dx.doi.org/doi: 10.1016/j.urology.2016.09.029.

[6]. Braga LH, McGrath M, Farrokhyar F, Jegatheeswaran K, Lorenzo AJ,

[7]. Associations of Initial Society for Fetal Urology Grades and Urinary Tract Dilation Risk Groups with Clinical Outcomes in Patients with Isolated Prenatal Hydronephrosis, The Journal of Urology® (2016),doi: 10.1016/j.juro.2016.08.099.

[8]. Marcio L.P. Lobo, Luciano A. Favorito, Marcelo Abidu-Figueiredo, Francisco J.B. Sampaio. Renal Pelvic Diameters in Human Fetuses: Anatomical Reference for Diagnosis of Fetal Hydronephrosis. Urology February 2011; Volume 77(2):452-457

[9]. Carr MC, Kim SS.: Prenatal management of urogenital disorders. UrolClin North Am 2010;37: 149-158.

[10]. Tiran Dias, ShanthiSairamShanyaKumarasiri: Ultrasound diagnosis of fetal renal abnormalities. Best Practice \& Research Clinical Obstetrics and Gynaecology 2014; $28: 403-415$.

Tables

Table1Expected Sonological Findings In Fetal Renal Anomalies( Original)

\begin{tabular}{|c|c|c|c|c|c|}
\hline Lesions & Kidneys & Ureters & Bladder & $\begin{array}{l}\text { Amniotic Fluid } \\
\text { Volume }\end{array}$ & $\begin{array}{l}\text { Expected } \\
\text { Outcome }\end{array}$ \\
\hline $\begin{array}{ll}\text { Unilateral } & \text { Renal } \\
\text { Agenesis } & \end{array}$ & Single Kidney & Not Seen & Normal & Normal & Good \\
\hline $\begin{array}{ll}\text { Bilateral } & \text { Renal } \\
\text { Agenesis } & \\
\end{array}$ & Not Seen & Not Seen & Not Seen & Decreased & Stillbirth \\
\hline $\begin{array}{l}\text { Infantile } \\
\text { Polycystic Disease } \\
\text { (Potter I) }\end{array}$ & $\begin{array}{l}\text { Homogenous } \\
\text { Enlargement } \\
\text { (Microcystic) }\end{array}$ & Not Seen & Small & Decreased & Stillbirth \\
\hline $\begin{array}{l}\text { Multicystic Renal } \\
\text { Disease (Potter Ii) }\end{array}$ & & & & & \\
\hline Unilateral & $\begin{array}{lll}\text { Large } & \text { With } & \text { Big } \\
\text { Cysts } & & \\
\end{array}$ & Not Seen & Normal & Normal & Good \\
\hline Bilateral & $\begin{array}{lll}\text { Large } & \text { With Big } \\
\text { Cysts } & & \\
\end{array}$ & Not Seen & Not Seen & Decreased & Stillbirth \\
\hline $\begin{array}{l}\text { Adult Polycystic } \\
\text { Disease (Potter Iii) }\end{array}$ & Large Cysts & Not Seen & Normal & $\begin{array}{l}\text { Probably } \\
\text { Normal }\end{array}$ & $\begin{array}{l}\text { Good Until } \\
\text { Adulthood }\end{array}$ \\
\hline \multicolumn{6}{|l|}{$\begin{array}{l}\text { Cystic Dysplasia } \\
\text { (Potter Iv) }\end{array}$} \\
\hline $\begin{array}{l}\text { Urethral } \\
\text { Obstruction }\end{array}$ & Hydronephrotic & Hydroureter & Enlarged & $\begin{array}{l}\text { Decreased If } \\
\text { Severe }\end{array}$ & $\begin{array}{l}\text { Usually } \\
\text { Poor }\end{array}$ \\
\hline $\begin{array}{l}\text { Ureterovesical } \\
\text { Junction } \\
\text { Obstruction } \\
\end{array}$ & Hydronephrotic & Hydroureter & $\begin{array}{lr}\begin{array}{l}\text { Normal } \\
\text { (May }\end{array} & \text { Size } \\
\text { Ureterocele) } \\
\end{array}$ & Normal & $\begin{array}{l}\text { Good After } \\
\text { Surgery }\end{array}$ \\
\hline $\begin{array}{l}\text { Ureteropelvic } \\
\text { Junction } \\
\text { Obstruction }\end{array}$ & Hydronephrotic & Not Seen & Normal & Normal & $\begin{array}{l}\text { Good After } \\
\text { Surgery }\end{array}$ \\
\hline
\end{tabular}


Antenatal Screening And Sonological Detection Of Urinary Tract Anomalies.

\begin{tabular}{|l|l|l|l|l|l|}
\hline $\begin{array}{l}\text { Primary } \\
\text { Megaureter }\end{array}$ & $\begin{array}{l}\text { Mild Dilatation Of } \\
\text { Renal Pelvis }\end{array}$ & Hydroureter & Normal & Normal & Good \\
\hline $\begin{array}{l}\text { Primary } \\
\text { Megacystis }\end{array}$ & Hydronephronic & Hydroureter & $\begin{array}{l}\text { Grossly } \\
\text { Enlarged }\end{array}$ & $\begin{array}{l}\text { Normal Or } \\
\text { Decreased }\end{array}$ & Poor \\
\hline $\begin{array}{l}\text { Primary } \\
\text { Vesicoureteral } \\
\text { Reflux }\end{array}$ & Hydronephrotic & Hydroureter & $\begin{array}{l}\text { Grossly } \\
\text { Enlarged }\end{array}$ & $\begin{array}{l}\text { Normal Or } \\
\text { Decreased }\end{array}$ & Poor \\
\hline Solid Tumors & Large Solid & Not Seen & Normal & Normal & $\begin{array}{l}\text { Good After } \\
\text { Surgery }\end{array}$ \\
\hline
\end{tabular}

Table2 Case Distribution Of Diagnosed Urogenital Anomalies(Original)

\begin{tabular}{|c|c|c|}
\hline Sl.No. & Anomalies & No. Of Cases \\
\hline 1. & Renal Agenesis & 1 \\
\hline 2. & $\begin{array}{l}\text { Cystic Renal Disease } \\
\text { Multicystic Renal Dysplasia }\end{array}$ & 1 \\
\hline 3. & $\begin{array}{c}\text { Renal Malpositions\& Shape Abnormality } \\
\text { Crossed Renal Ectopia } \\
\text { Pelvic Kidney }\end{array}$ & $\begin{array}{l}2 \\
1\end{array}$ \\
\hline 4. & Renal Tumors & 2 \\
\hline 5. & $\begin{array}{l}\text { Dilatation Of Urinary Tract } \\
\text { Pelviectasis } \\
\text { Caliectasis }\end{array}$ & $\begin{array}{l}3 \\
1\end{array}$ \\
\hline 6. & $\begin{array}{l}\text { Upper Urinary Tract Obstruction } \\
\text { Pelviureteric Junction Obstruction } \\
\text { Vesicoureteric Junction Obstruction }\end{array}$ & $\begin{array}{l}9 \\
1\end{array}$ \\
\hline 7. & $\begin{array}{l}\text { Lower Urinary Tract Obstruction } \\
\text { Obstruction Secondary To Ureterocele } \\
\text { Vesicoureteric Reflux } \\
\text { Posterior Urethral Valve } \\
\text { Urethral Atresia }\end{array}$ & $\begin{array}{l}1 \\
2 \\
2 \\
1\end{array}$ \\
\hline 8. & Bladder Extrophy & 2 \\
\hline 9. & $\begin{array}{l}\text { Genital Tract Anomalies } \\
\text { Bilateral Hydrocele } \\
\text { Ovarian Cyst }\end{array}$ & $\begin{array}{l}1 \\
1\end{array}$ \\
\hline
\end{tabular}

Table3-Case Distribution Of Final Diagnosis In Fetuses With Antenatal Diagnosis Of Hydronephrosis(Original)

\begin{tabular}{|c|l|l|l|}
\hline Sl.No & Anomalies & $\begin{array}{l}\text { No.Of } \\
\text { Cases }\end{array}$ & Percent \\
\hline 1. & Pelviureteric Junction Defect & 9 & $47.3 \%$ \\
\hline 2. & Vesocpireteric Junction Defect & 4 & $21.1 \%$ \\
\hline 3. & Vesicoureteric Reflux & 2 & $10.5 \%$ \\
\hline 4. & Posterior Urethral Valve & 2 & $10.5 \%$ \\
\hline 5. & Obstn.Secondary To Ureterocele & 1 & $5.26 \%$ \\
\hline 6. & Urethral Atresia & 1 & $5.26 \%$ \\
\hline
\end{tabular}

Table4-Case Distribution Of Anomalies Associated With Severe Oligohydramnios Which Underwent

Termination Of Pregnancy(original)

\begin{tabular}{|r|l|l|l|}
\hline Sl.No & Type & No.Of Cases & Percentage \\
\hline 1. & $\begin{array}{l}\text { Anomaly Associated With } \\
\text { Oligohydramnios }\end{array}$ & 3 & $42.8 \%$ \\
\hline 2. & $\begin{array}{l}\text { Anomaly Associated Without } \\
\text { Oligohydramnios }\end{array}$ & 7 & $57.2 \%$ \\
\hline
\end{tabular}

\section{Legends for figures}

Fig 1- Unilateral renal agenesis: 21 wks gestation, transverse view shows normal right while the other side shows only bowel.

Fig 2-Unilateral multicystic renal dysplasia (Potter's Type II): 23 wks gestation, longitudinal and transverse views showing mildly enlarged renal size with multiple large cysts of varying sizes in the right kidney.

Fig 3- 32wks gestation, transverse and longitudinal views showing bilateral gross hydronephrosis due to PUJ obstruction

Fig 4-Posterior urethral valve: 18 wks gestation, (a) longitudinal view shows megacystis, (b) transverse view showing the "keyhole Phenomenon" with small amount of ascites, (c) longitudinal view showing severe distension of the ureter and unilateral hydronephrosis

Fig 5- Mesoblastic Nephroma:28wks gestation, longitudinal view showing a solid, fairly homogenous mass arising from left kidney with small amount of normal renal tissue identified 
Fig 1

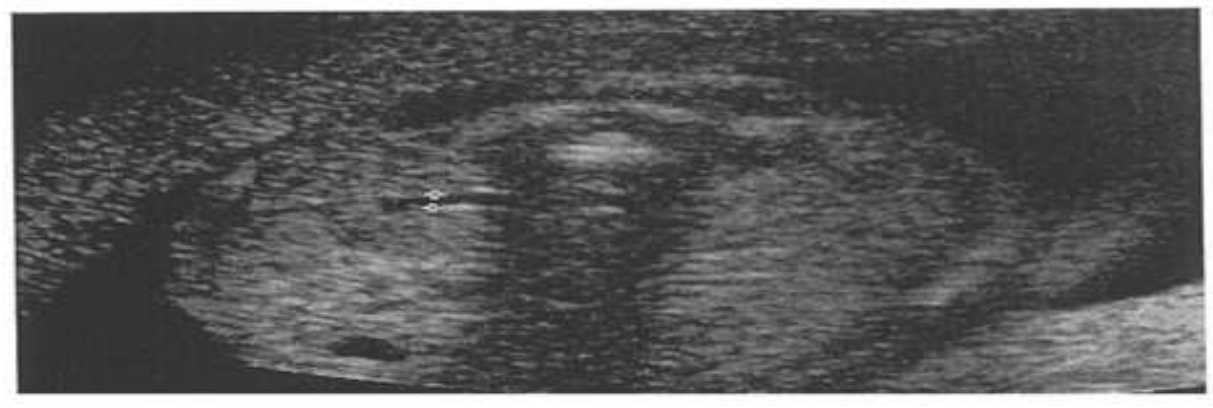

Fig 2
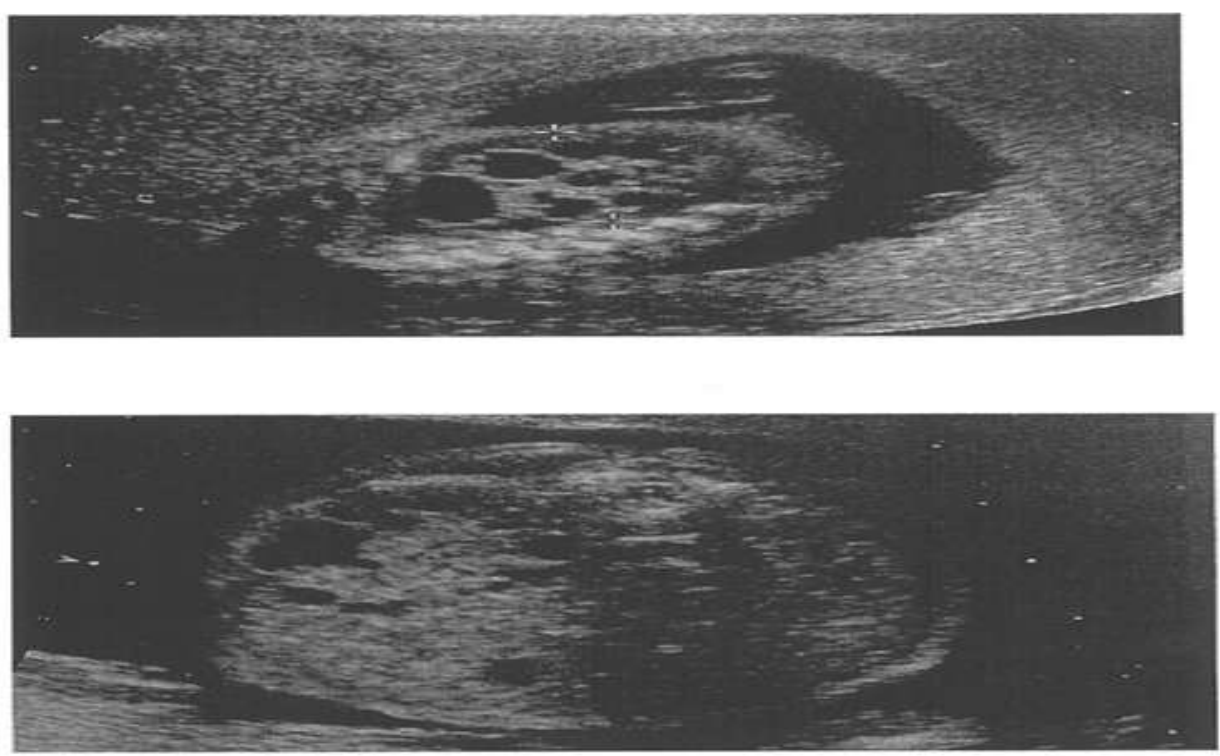

Fig3
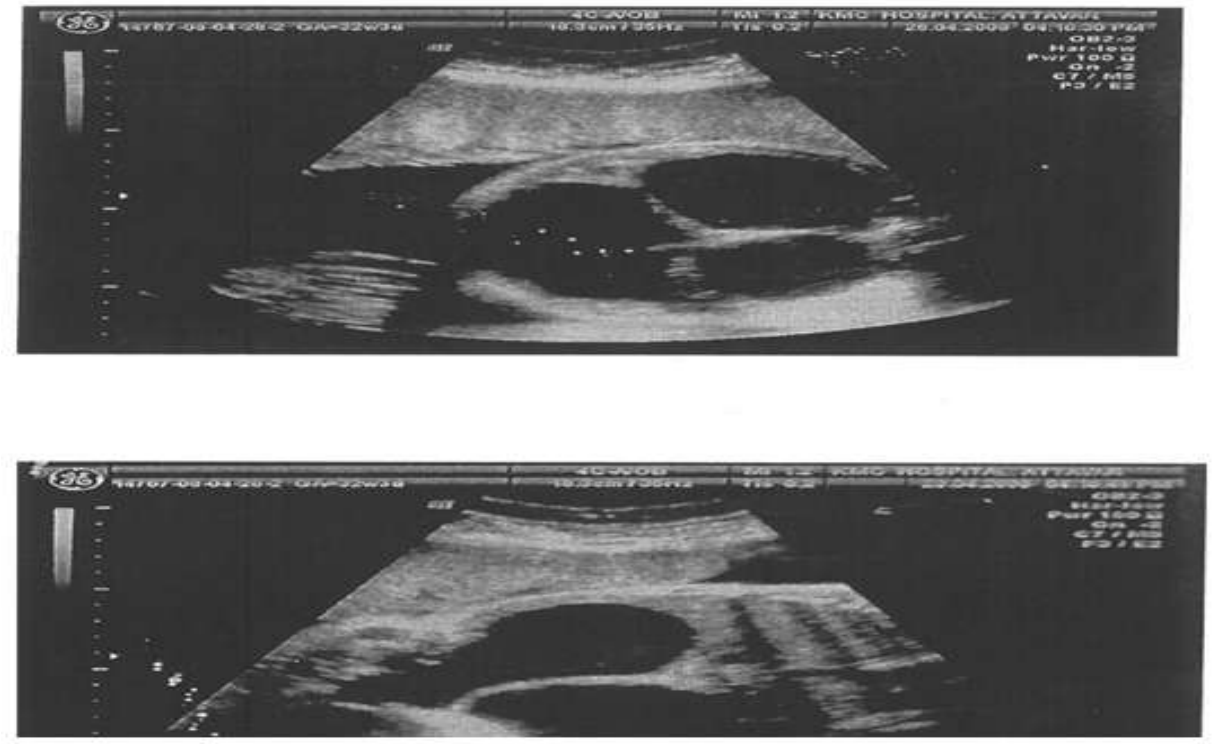

Fig 4 


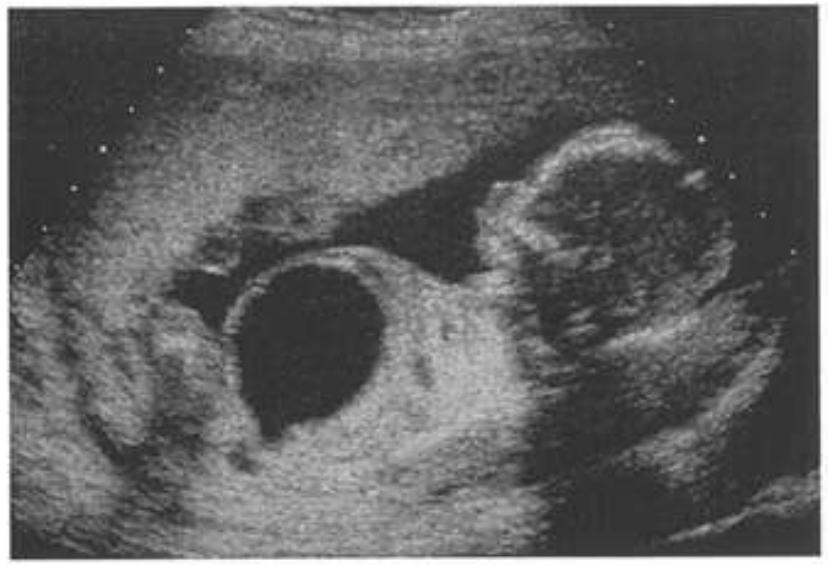

a

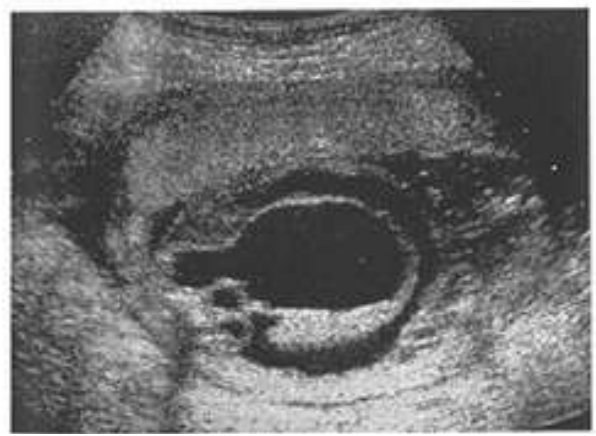

\section{Fig5}

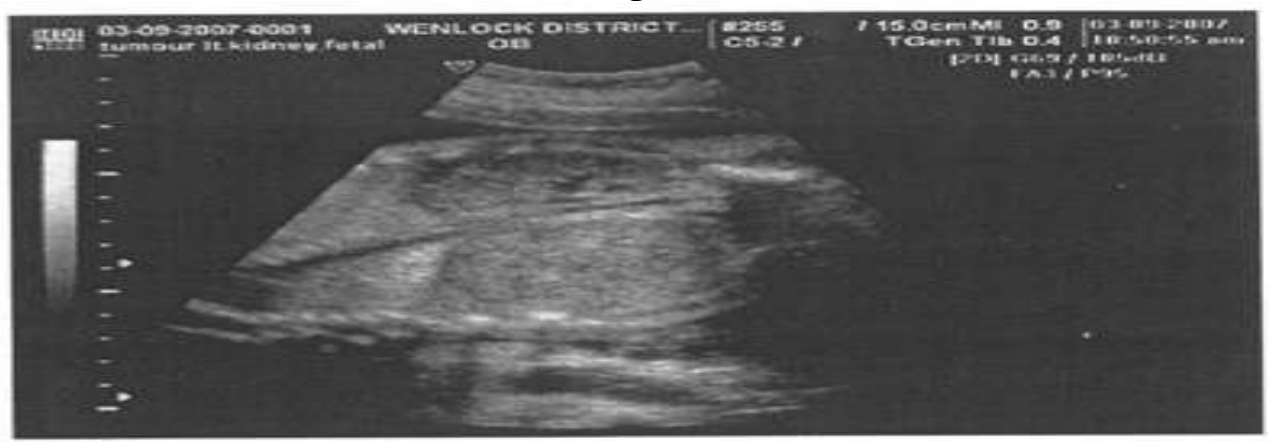

